\title{
Transnational Adoption and European Immigration Politics: Producing the National Body in Sweden
}

\author{
Barbara Yngvesson \\ Hampshire College, byngvesson@hampshire.edu
}

Follow this and additional works at: https://www.repository.law.indiana.edu/ijgls

Part of the Comparative and Foreign Law Commons, European Law Commons, Family Law Commons, Immigration Law Commons, International Law Commons, and the Law and Politics Commons

\section{Recommended Citation}

Yngvesson, Barbara (2012) "Transnational Adoption and European Immigration Politics: Producing the National Body in Sweden," Indiana Journal of Global Legal Studies: Vol. 19 : Iss. 1 , Article 12.

Available at: https://www.repository.law.indiana.edu/ijgls/vol19/iss1/12

This Symposium is brought to you for free and open access by the Law School Journals at Digital Repository @ Maurer Law. It has been accepted for inclusion in Indiana Journal of Global Legal Studies by an authorized editor of Digital Repository @ Maurer Law. For more information, please contact rvaughan@indiana.edu.

\section{$\Psi$}

JEROME HALL LAW LIBRARY

INDIANA UNIVERSITY

Maurer School of Law
Blooming ton 


\title{
Transnational Adoption and European Immigration Politics: Producing the National Body in Sweden
}

\author{
BARBARA YNGVESSON*
}

\begin{abstract}
This article explores the role of transnational adoption in the production of a multicultural but Swedish national body during the second half of the twentieth and the first decade of the twenty-first century, when Sweden became a multiethnic, multicultural, and racially divided country. I examine the development of international adoption policies in the 1970s, 1980s, and 1990s, emphasizing the erasure of the child's connection to a preadoptive past, even as the child's cultural difference was celebrated in adopting nations. In Sweden, which in the late 1970s and early 1980s had the world's highest adoption ratio (number of transnational adoptions per 1000 live births), debates about the Swedishness of the adoptee and the difference of the immigrant child underscored the assumption that the former but not the latter could become completely Swedish, while hinting at the (in)significance of race in constituting Swedish identity. My research situates transnational adoption in the context of technologies of exclusion that regulate the national body and the complex position of the adoptee as an incorporated but excluded other in adopting nations.
\end{abstract}

He who has been banned is not, in fact, simply set outside the law and made indifferent to it but rather abandoned by it, that is exposed and threatened on the threshold in which life and law, outside and inside, become indistinguishable. ${ }^{1}$

* Professor Emerita of Anthropology, Hampshire College. This article was completed while participating in project $\mathrm{I}+\mathrm{D}$ CS02009-14763-C03-01 financed by the Ministry of Science and Innovation of Spain. Unless otherwise noted, all translations are my own.

1. Giorgio Agamben, Homo SACER: SOVEREIGN POWER AND BARE Life 28 (1998).

Indiana Journal of Global Legal Studies Vol. 19 \#1 (Winter 2012)

(C) Indiana University Maurer School of Law 


\section{INTRODUCTION}

In this paper, I address what seems to be a paradox of current transnational adoption practice. On the one hand, national adoption laws in Euro-American adopting nations and The Hague Conference of 29 May 1993 on Protection of Children and Co-operation in Respect of Intercountry Adoption (Hague Adoption Convention) ${ }^{2}$ privilege so-called strong or plenary adoptions in which there is a legal "clean-break" between the adopted child and its preadoptive kin. ${ }^{3}$ The clean break is contingent, in turn, on a child's orphan status; this is determined by the sending or giving country and establishes that it was legally abandoned-that is, that its abandonment was not induced or coerced, but freely consented to by the parent. The legal fiction of every adopted child's orphan status and the freedom of the birth parent in abandoning it are a prerequisite for the child's incorporation into its adoptive family and nation as if it had no other parents and were that family's or nation's own. ${ }^{4}$

In sharp contrast to the clean-break policy and the erasure of origins that entails, there has been a marked movement of adoptees back to the cut-off birth nation, especially in the 1990s and first few years of the $2000 \mathrm{~s}$, to connect with their cultural heritage through roots trips and heritage tours, and to reconnect with birth kin through processes of search and reunion. This movement "back" to a past that officially does not exist coincided with a period of rapid growth during which transnational adoptions to all receiving nations peaked in 2004 at 45,016 adoptions. ${ }^{5}$ It also coincided with the normalization of so-called "culture keeping" in the adopting nation-culture camps, language classes, and so forth-that emerged in the late twentieth century as an effort to restore to the adopted child the culture that this child was presumed to have lost. Heather Jacobson describes culture keeping as a form of "ethnic labor" engaged in especially by white adoptive mothers,

2. Hague Conference on Private International Law: Final Act of the 17th Session, Including the Convention on Protection of Children and Co-operation in Respect of Intercountry Adoption, May 29, 1993, 32 I.L.M. 1134 (1993) Thereinafter Hague Conference].

3. William Duncan, Regulating Intercountry Adoption: An International Perspective, in FronTIERs of Family LaW 46, 51-53 (Andrew Bainham \& David S. Pearl eds., 1993).

4. JUDITH S. MODELL, KINSHIP WITH STRANGERS: ADOPTION AND INTERPRETATIONS OF KINSHIP IN AMERICAN CULTURE 2 (1994) (discussing the "as-if-begotten" nature of adoptive kinship).

5. Peter Selman, The Movement of Children for International Adoption: Developments and Trends in Receiving States and States of Origin, 1998-2004, in INTERNATIONAL adoption: Global Inequalities and the Circulation of Children 32, 34 (Diana Marre \& Laura Briggs eds., 2009). 
particularly by those whose children are understood to be racial minorities. ${ }^{6}$ An example of culture keeping in the United States appears in an article in The New York Times, which quoted the mother of a child adopted from China who was sending her daughter to the Shaung Wen Academy, a school on the eastern border of Chinatown in Manhattan where most of the students are children of Chinese immigrants. The mother explained "[w]e really want Youjing to learn the language. . . . We want her to look Chinese and feel Chinese."' In other cases, parents "are learning Spanish with their children in the evenings and following cookbook instructions to create casseroles of kimchi, a Korean preserved vegetable, on weekends. They decorate their homes with Korean fans, Chinese calligraphy and posters of the Andes." ${ }^{8}$ These parents, "mostly white and middle class, want to give their children's birth cultures back to them. . . Their fear is that their children could grow up to be Chinese, Korean or Mexican on the outside only" (emphasis added). ${ }^{9}$

The turn to culture keeping emerged in part as a response to the concern of sending countries that their most precious resourceschildren-were being lost to international adoption. ${ }^{10}$ Such concerns contributed to the inclusion in the Hague Adoption Convention of provisions mandating the preservation of information about the child's origin, "in particular, information concerning the identity of his or her parents," and ensuring that the child or the child's representative has access to this information. ${ }^{11}$. But the movement to acknowledge the origins of the adopted child emerged no less in response to concerns of adult adoptees, and in some cases, of their adoptive parents. ${ }^{12}$ The shift in emphasis over the past decade and a half toward recognition, rather than mandated forgetting, of the origins of the adopted child has contributed to transformations in adoption practice, but it has not

6. Heather Jacobson, Culture Keeping: White Mothers, International ADOPTION, AND THE NEGOTIATION OF FAMILY DIFFERENCE 68 (2008).

7. Yilu Zhao, Living in 2 Worlds, Old and New: Foreign-Born Adoptees Explore Their Cultural Roots, N.Y. Times, Apr. 9, 2002, at B1.

8. $I d$.

9. $I d$.

10. Richard R. Carlson, The Emerging Law of Intercountry Adoptions: An Analysis of the Hague Conference on Intercountry Adoption, 30 TULSA L.J. 243, 256-57 (1994).

11. Hague Conference, supra note 2, art. 30.

12. Barbara Yngvesson, Going "Home": Adoption, Loss of Bearings, and the Mythology of Roots, in CUlTURes of TRANSNATIONAL ADOPTION 25, 34-44 (Toby Alice Volkman ed., 2005); Barbara Yngvesson, "Un Niño de Cualquier Color": Race and Nation in Intercountry Adoption, in Globalizing INSTITUTIONS: CASE STUDIES IN REGULATION AND INNOVATION 169, 192-99 (Jane Jenson \& Boaventura de Sousa Santos eds., 2000). 
affected the official construction of the child's orphan status in the sending country and "as-if-begotten" status in the adoptive family. ${ }^{13}$

The focus of this Article is on the relationship of the clean break in adoption, and the legal abandonment it requires, with the construction of the adopted child's belonging - the official inclusion of the child-not only in the adopting nation, but in the sending nation as well. The Article builds on Giorgio Agamben's discussion of "limit figures," such as the refugee, in constituting a "radical crisis of every possibility of clearly distinguishing between membership and inclusion, between what is outside and what is inside" a juridical order. ${ }^{14}$ Legal abandonment produces a child that is construed as "in its core . . . kulturlos [cultureless],"15 in this way constituting it as free to be incorporated fully in its new family and nation or, alternatively, as free to return to the birth nation. In this sense, the adoptee is arguably the ultimate liberal subject, one whose culture is not a matter of "substantial belonging" but rather of "idiosyncratic personal choice or opinion." 16 Yet as the turn to culture keeping in transnational adoption suggests, the condition of "culturelessness" in the adoptee seems to call forth the need for an origin that is understood as preceding its legal abandonment in the sending nation and its inclusion by law in the adopting nation. This experienced need pulls the adoptee- or, as in Jacobson's discussion, the adoptive parents-back to what is posited as the "real" or "natural" ground of belonging. In this way, the adoptee-unlike the immigrant, as I will argue below-can be transformed in the adopting nation into an emblem of the culture that the child has lost. This culture is valued as a "property" of the child and, through the incorporation of the child, of the nation to which this child belongs but does not threaten the smooth incorporation of difference on which international adoption-and its contribution to the multiculturalism of the adopting nation-is premised.

What does it mean to give culture or origins "back" to an adopted child, whether by performing culture in the adopting nation or discovering culture in the sending nation? What are the implications of this giving for our understanding of what it means to "originate"? Finally, in what ways does the emergence of "culture" in the negative space of irrevocable relinquishments, sealed records, and enforced cutoffs from a child's preadoptive past illuminate the blind spots on which

13. JUDITH S. MODELL, KINSHIP WITH STRANGERS: ADOPTION AND INTERPRETATIONS OF KINSHIP IN AMERICAN CULTURE 2 (1994).

14. AGAMBEN, supra note 1 , at 25.

15. Slavoj Žižek, Tolerance as an Ideological Category, 34 CRITICAL INQUIRY 660, 662 (2008).

16. Id. at 663 . 
any cultural system depends for its consistency? And how does the adoptee's "need" to return shed light on the productivity of this negative space?

This Article examines the figuring of culture and of national belonging in the erasures mandated by domestic adoption laws and the Hague Adoption Convention. The Article is based on archival and ethnographic research in Sweden, India, Colombia, and Chile between 1995 and 2008, and it is centered on adoptions arranged by the Swedish agency, Adoption Centre, one of Europe's largest and most prestigious adoption organizations, between 1964 and the early 1980s. I focus specifically on interviews with adults who were adopted by Swedish parents during this period and have returned one or more times to their countries of birth to visit their birth families or the orphanages where they spent the first years of their lives. ${ }^{17}$

\section{AdOPTION POLICY, MUlTiCUltuRALISM, AND "NON-NORDIC GROWTH" IN SWEDEN}

To provide a little background and situate Sweden in the arena of transnational adoption: in 2010, with 655 such adoptions, Sweden was the seventh largest adopter of the world's twenty-three major adopting nations. ${ }^{18}$ Since the beginning of transnational adoptions during the Korean War, Sweden, with a population today of around nine million, has adopted approximately 50,000 children from Asia, Africa, North and South America (including the United States), and Eastern Europe. ${ }^{19}$ The principal adopting nation today, as it has been for the past five

17. Between 1999-2006, I attended events and meetings organized by Adoption Centre or by adopted adults, mostly in Stockholm, read memoirs, and watched documentaries written by or focused on the experiences of adopted adults in Sweden, and conducted interviews with twenty-four adopted adults or young adults between the ages of sixteen and thirty-six who were born in Ethiopia, Chile, Colombia, India, and Korea. I also accompanied a group of twelve Swedish families with children adopted from Chile on a two-week "roots trip" organized by Adoption Centre. On that trip, I acted as interpreter at a meeting of an adoptee, her adopted mother, and her birth mother. Following the trip, I conducted follow-up interviews in Sweden with the parents and children, as well as staff from Adoption Centre who organized the trip.

18. Peter Selman, The Rise and Fall of Intercountry Adoption in the 21st Century, 52 INT'L SoC. WORK 575 (2009) (tables updated yearly by Peter Selman, updated table for 2010 on file with author). Selman notes that the number of adoptions for Sweden in 2010 includes only those registered by agencies, and thus may not reflect the actual number of adoptions. Personal Correspondence with Peter Selman, Visiting Fellow at Newcastle University, Newcastle upon Tyne, U.K. (Sept. 23, 2011).

19. SWEDISH INTERCOUNTRY ADOPTIONS AUTH. [MIA], SURVEY OF THE NUMBER OF Foreign Adoptive Children Placed INTo Swedish Families OVER THE Years 1969 2009 BY COUNTRIES OF ORIGIN, available at http://www.mia.eu/english/totals.pdf. 
decades, is the United States, which adopted 12,149 children in 2010, but in 2004, the peak year of international adoptions, received 22,884 children, which was just under half of all the children adopted transnationally that year. ${ }^{20}$

While Sweden is not a large international adopter in terms of sheer numbers, it has one of the world's highest adoption ratios-the proportion of international adoptees relative to the number of live births in a country in any given year. ${ }^{21}$ In 1978, a year in which Sweden adopted approximately 1,600 children internationally, its adoption ratio, at 17.4 international adoptions for every 1,000 live births, was equivalent to a rise of 0.2 in the crude birth rate. ${ }^{22}$ Sweden's adoption ratio dropped in subsequent years as its number of adoptions fell. Its adoption ratio in 1998 was 10.8 ; in 2004 it was 11.7 ; and in 2008 it was 7.4 - once again the highest ratio among adopting nations, at a time of sharp declines in international adoptions. ${ }^{23}$ The United States, by contrast, in spite of being the world's major international adopter in terms of absolute numbers, had an adoption ratio of 2.0 in 1989 , of 4.2 in 1998 , of 5.5 in 2004 , and of 4.0 in 2008 , a much smaller number of international adoptees relative to live births over time. ${ }^{24}$

Sweden's significance in the field of international adoption is also related to its explicit commitment to adoption as a way of building a multicultural nation. The founders of international adoption in late 1960 s Sweden argued that Sweden was "a well prepared soil for the idea of inter-country adoption to grow," because of its egalitarian ethos, the absence of racism, the fact that Sweden had "no colonial history," and the prevalence of an ideology that valued nurture over nature. ${ }^{25}$ The Swedish adopters felt that "it didn't matter that the child came from another country or that he had another genetic heritage, once he was adopted into his family and new society he would become fully 'Andersson' and fully Swedish, integrated with the family as well as a citizen." 26

20. Selman, supra note 18.

21. Peter Selman, Intercountry Adoption in the New Millennium: The "Quiet Migration" Revisited, 21 POPULATION RES. \& POL'Y REV. 205, 212 (2002).

22. Peter Selman, The "Quiet Migration" in the New Millennium: Trends in Intercountry Adoption 1998-2003 (Aug. 10-12, 2005) (presented at the 8th Global Conference on Adoption in Manila).

23. Peter Selman, Trends in Intercountry Adoption: Analysis of Data from 20 Receiving Countries, 1998-2004, 23 J. POPULATION RES. 183 (2006) (tables updated yearly by Peter Selman, updated table for 2008 on file with author).

24. Selman, supra note 21, at 213; Selman, supra note 23.

25. GUNILLA ANDERSSON, INTERCOUNTRY ADOPTION IN SWEDEN: THE EXPERIENCE OF 25 YEARS AND 32,000 PLACEMENTS 2 (1991).

26. Id. 
While Sweden was viewed by the earliest international adopters as an ideal environment for absorbing what was described at the time as the "different" child, the child's full incorporation was contingent on its orphan status-its irrevocable separation from preadoptive kin. The orphan status of the child, in turn, was linked to assumptions that the historical child-the child whose abandonment was an effect of such social, political, and economic conditions as the poverty of its parents, the marital status of its mother, its skin color, its gender, its health status, and so forth-could be canceled with the legal abandonment of the child. ${ }^{27}$ This would make room for a "generalized child" — a child like any other, a "child of any color"-who could belong anywhere, as long as its adoptive parents-and specifically its adoptive mother-were sufficiently attentive to the child's needs, assumed to be the need for "a family." 28 The tension between a generalized child whose greatest need is for parents and the racialized child that reemerges in the adoptive family and nation is a key dimension of the adoptee's need to return, a theme to which I return below.

The assumptions about the adopted child who simply needs loving parents to be transformed into a fully Swedish citizen were in marked contrast to Sweden's policy of managing immigrants, which according to a critic of the policy, Mauricio Rojas, generated "the worst possible type of ethnic fragmentation a nation can have, one that gives rise to increasing conflicts between different population groups, producing a sense of disdain and fear in the majority, and a bitter sense of resistance among minorities." ${ }^{29}$ Rojas attributes this fragmentation to the very emphasis on preservation of culture-the "ethnic, religious and linguistic minorities' possibility to retain and develop its own culture and social life"-that was a cornerstone of Sweden's plan for a multicultural society in the second half of the twentieth century. ${ }^{30}$ For example, Swedish immigration policies in the 1960s and early 1970s consisted of a "socially engineered pluralism,"31 a policy which encouraged immigrants to vote in local elections, supported immigrant newspapers, and under which the state provided support for native language classes in public schools. ${ }^{32}$ Immigrants were given "the opportunity to choose the extent to which they adopt[ed] a Swedish

27. Barbara YNGVEsson, BELONGING IN AN ADOPTED WoRLd: RACE, IDENTITY, AND TRANSNATIONAL ADOPTION 42-43 (2010).

28. Id. at $28,89-91$.

29. MAURICIO ROJAS, SVERIGES OÄLSKADE BARN: ATT VARA SVENSK MEN ÄNDÅ INTE [SWEDEN's UNLOVED CHILDREN: To BE SWEDISH BUT YET NOT SWEDISH] 92 (1995).

30. Id.

31. allan Pred, Even in Sweden: Racisms, Racialized Spaces, and the Popular GEOGRAPHICAL IMAGINATION 47 (2000).

32. Id. at 45 . 
cultural identity or maintain[ed] and develop[ed] their original identity," 33 an approach accompanied by "a pronounced selfrighteousness, an unshakable belief that Sweden really was the best in the world at formulating immigrant and refugee policies." 34

This period of the 1960s and 1970s marked a transition between what Christopher Caldwell describes as the gradual phase, from 1947 to 1967, and "the 'sudden' phase of the emergence of multi-ethnic Sweden" in the late 1970s, 1980s, and 1990s. ${ }^{35}$ For Swedish policymakers at the time, "multiethnic" meant pizza places, kebab bars, ethnic markets, and immigrant associations. ${ }^{36}$ But none of these were imagined as disturbing the taken for granted, the deep and unchanging level of cultural values, which "were assumed to coincide with the Swedish, with Swedishness"(emphasis added). ${ }^{37}$ Jane Kramer describes this attitude in a 2005 issue of The New Yorker magazine. Commenting on the violence that erupted in immigrant housing projects surrounding France's big cities that year, she compared the French perspective on immigrants"You will be us"-to that of the British-"You will never be us"- to the Scandinavian alternative - "We'll support you, but please be invisible until you are us." 38

But becoming "us" was increasingly difficult as Sweden's open-door policy for refugees in the 1980s led to a tripling of asylum seekers, from 5,000 annually in the early 1980 s to 15,000 by the end of the decade, with an influx of Middle Easterners, Latin Americans, Africans, and Southeast Asians. ${ }^{39}$ This pattern became known in Sweden as "nonNordic growth."40 By 1989, Sweden had tightened its immigration policy and the number of refugee seekers diminished. ${ }^{41}$ Nonetheless, by the 1990s, with many non-European immigrants confined to de facto segregated housing developments where unemployment rates in some areas were as high as eighty percent, negative stereotyping and increasingly violent forms of racism became commonplace. ${ }^{42}$ Today, nearly a quarter of Sweden's population is foreign born or has a foreign

33. Id. (internal quotation marks omitted) (quoting reform legislation from the mid1970s).

34. Id. at 44 (quoting a 1997 editorial by Sverker Björk).

35. Christopher Caldwell, Islam on the Outskirts of the Welfare State, N.Y. TIMES, Feb. 5,2006 , at E54.

36. RoJAS, supra note 29 , at 99.

37. Id.

38. Jane Kramer, Comment, Difference, New YoRKER, Nov. 21, 2005, at 41.

39. Anna Westerståhl Stenport, Bodies Under Assault: Nation and Immigration in Henning Mankell's Faceless Killers, 79 SCANDINAVIAN STUD. 1, 7 (2007).

40. PRED, supra note 31 , at 35-36.

41. Stenport, supra note 39 , at 9.

42. Id.; see also Caldwell, supra note 35 , at E56-58. 
parent, and the intensification of anti-immigrant sentiment that has accompanied this transformation was apparent in the success of the far right party, campaigning on an anti-immigrant platform in September 2010 , in winning a sufficient number of votes to be seated in the Swedish Parliament for the first time. ${ }^{43}$

During this period of growing concern about the impact of immigrants on Swedish society, and specifically in light of the country's humanitarian image as "democratic, anti-colonialist, anti-racist, and anti-Nazi," 44 the intercountry adoptee came to assume a key role in Sweden's multicultural project. This was made possible by the child's incorporation into what Swedish adoption officials described informally as "an educated Swedish family," one that officials assumed would support the child's racial difference while at the same time enabling the adoptee's transformation into a completely Swedish child. ${ }^{45}$ For example, a heated debate in the adoptive parent journal Att Adoptera in the mid-1970s was focused on the question of whether the adopted child was or was not an "immigrant child." 46 Noting that the distinction between the two could be "very difficult, sometimes almost impossible to grasp for many," 47 Adoption Centre president Madeleine Kats argued nonetheless in a 1975 editorial in Att Adoptera that it was significant:

The immigrant child comes together with its familypappa, mamma, siblings, perhaps father's mother or mother's mother. If the child comes from Turkey, they speak Turkish at home, cook Turkish food, socialize with other Turkish families, continue to live according to a Turkish pattern. The child's family situation and home life doesn't change much because the family moves to Sweden. The problems tend to arise when the child is

43. Suzanne Daley, Swedes Begin to Question Liberal Migration Tenets, N.Y. TIMES, Feb. 27, 2011, at A6.

44. Stenport, supra note 39 , at 1,5 (quoting LARS-ERIC HANSEN, JÄMLIKHET OCH VALFRIHET: EN STUDIE AV DEN SVENSKA INVANDRARPOLITIKENS FRAMVÄXT [Equality and Freedom of Choice: A Study of Swedish Immigration Policy] 227 (2001)).

45. Significantly, when adoptions in the former Soviet Union opened up in the 1990s and Swedish adoption organizations, in response to parent demand, began setting up adoption programs in that region, parents who opted for the children who became available (many of whom were older and had been institutionalized for a period of years) were described by representatives of Adoption Centre as "less educated" because of their preference for what were understood to be "same race" children (author's observation in the course of fieldwork).

46. YNGVESSON, supra note 27 , at 97.98 (quoting Madeleine Kats, Är adoptivbarn invandrarbarn? [Are Adoptive Children Immigrant Children?], 6 ATT ADOPTERA 124 (1975)).

47. Id. 
torn apart (slitas) by the difference between two cultures, living according to one pattern in school and among his friends, and according to another at home and together with other families "from home."

The adopted child, by contrast, comes alone to a wildly different (vilt främmande) family, perhaps the first the child has ever had. The family doesn't speak the child's language, it lives in a Swedish way, socializes with Swedish families, usually knows very little about how the child lived before it came, which values applied in raising it-indeed, often the family doesn't even understand what the child is saying because it speaks an unknown language, Korean or Marathi, or Amharic . ..

The immigrant child's problems tend to be social. The family perhaps lives in poor conditions, by Swedish standards. They have little money, the parents must work hard just to get by and the children are expected to help, take care of the house, mind younger siblings, and so forth ....

The adopted child's problems are seldom social-the parents generally live in secure economic circumstances, take time off to be together with their children, demand no work from the child at home, and support the child in all ways so that it will blend in to Swedish society.

The adopted child's problems are not social, they are emotional....48

This depiction of the radical difference between immigrant and adoptee points to the key role of the child's abandonment in its belonging in Sweden. The child's abandonment guarantees its inclusion, in that it triggers a humanitarian response-the child "needs" a family, parents are available who "need" a child, and together they produce a family like any other. By contrast, the immigrant child's difference was read as unbridgeable. Because this child inhabited an immigrant milieu-immigrant parents, other immigrant families-it would 
experience "violent culture clashes" upon its encounter with "Swedish society." 49

As this discussion suggests, the adoptive family assumes a key transformative role in Sweden's multicultural project. Its task becomes, in effect, the achievement of the twinned goals of embracing and supporting "otherness," which can be understood as "ethnicity" or "cultural" difference in the adoptee, while maintaining "Swedishness" as the template for national identity and real belonging. Embracing the child's otherness while transforming the child to be more like the parent was understood as the task of the adoptive parent; it was a task that created an emotional problem for the adopted child that centered on the value of the child's difference and the contradictions that surrounded this value. Only by performing her cultural difference, while ignoring her racialized body, could the adopted child "play the game" of the adoptive parents and the adopting nation, that race made no difference to belonging in Sweden.

\section{II. "ORIGINS" AND THE MYTH OF THE "COMPLETELy SWEDISH"}

Interviews with men and women who were adopted by Swedish parents in the late 1960 s and 1970 s suggest the tensions this policy produced in adoptees who experienced themselves as completely Swedish on the inside but were repeatedly questioned about their different appearances, coded as "origins," as they grew up. Here, for example, are the words of a young woman in her twenties who was interviewed in the mid-1990s about her connection to India, the nation in which she was born:

People have always reminded me about India, as long as I can remember, asking if I don't want to return. And when I reply that, actually, I have no interest in India, they don't believe me: "Just wait, little woman, that need will come." That kind of thing is incredibly frustrating! It makes me furious not to be respected. I have no need whatever to return to India, since I have no physical or emotional memories from there. 50

49. Id.

50. ANNA VON MELEN, SAMTAL MED VUXNA ADOPTERADE [CONVERSATIONS WTTH ADULT ADOPTEES] 115 (1998). 
Another woman, who was adopted from Ethiopia in the early 1970s as an infant, explained her decision to go back to Ethiopia in her early twenties as follows:

Well, I think one important thing is, to me it was important to go back, very much because so many people kept telling me about Ethiopia, and what Ethiopia is like: "It's awful. It is wonderful. It is great. It is horrible. It is poor. It is beautiful." I had heard so many different versions. And people kept asking me also if I had been back and I always had to answer: "No." And then they came, so many people who knew, mostly like people who would see me maybe on the bus and who would come up to me and say:

"Are you from Ethiopia?"

"Yeah."

"I could tell by your looks." And:

"Where are you from?"

"I'm from Ethiopia."

"I was almost going to guess, because you look very Ethiopian. Have you been to Ethiopia?"

"No, I haven't."

“Oooohh!"

And then there came this long story about what Ethiopia is. And I could never say: "Yeah, right!" or "No, I don't think so, I disagree!" because I didn't know. I was beginning to get rather bothered by that actually. I couldn't argue, I couldn't say anything. I just had to say, "Aha, really! Oh, is that so?" And it felt as if they knew something about me that I didn't know, because they were talking about my origin and they all attributed some importance to this. . . . It was really difficult to 
relate to, because they were relating to something I couldn't relate to. ${ }^{51}$

As these narratives suggest, the difficulties reported by adopted adults in their identification with birth or adoptive nations are entangled with the ways that the racialization of their bodies made it impossible for them to accept themselves as fully Swedish, even though their adopted status was meant to secure their belonging in Sweden. As one adult, Sara Nordin, who was adopted from Ethiopia when she was one year old noted in an interview in 2002: "There is an image of the adoptees as a group that does not stand out, because they are, after all, Swedish. But we look like any other African. So of course we cannot help but stand out." 52 Nordin described a particularly difficult period when she was fourteen or fifteen years old and there were "lots of race problems in school":

It was also a school with lots of immigrants. So there was a lot-the police were there, there was lots of fighting. So then I got into a strange situation, because I became almost an immigrant although I felt myself to be very Swedish (jättesvensk). And the immigrants thought I was like them. And my Swedish friends thought I was like them. And I couldn't really decide myself where I belonged. ${ }^{53}$

Another adopted adult, Eleonore Park-Edström, a Swedish journalist who was adopted from Korea as an infant by Swedish parents, noted in one of a series of seminars on racism for adoptive parents held in the early 1990s by Adoption Centre, "[y]our unease has been no less obvious than your propensity for simple solutions to complex problems. In your eagerness to be liberal-minded-we who adopt internationally are of course uniquely color-blind-you resort to the same simple concepts as the 'enemy haters' you so sincerely despise."54 Park-Edström pointed out that parents ask, "Why do adoptive children suffer? Our youngsters are Swedish children." She responded: "The question is absurd. Why shouldn't we suffer? Why should we be spared when the skinheads do their purifying among the

51. YNGVESSON, supra note 27, at 142.

52. Id. at 141 .

53. Id. at 130.

54. Eleonore Park-Edström, Tar vi vårt ansvar som invandrarfamilj? [Do We Accept Our Responsibility as an Immigrant Family?], 24 ATT ADOPTERA 6 (1993). 
handicapped, the refugees, and the gay.... Why do the Danish national socialists want to force adoptive children to be sterilized?"55

Park-Edström's seminars underscore the contradictions of a Swedish ideology that embraces the refugee and the immigrant, even as the "Swedishness" of the adoptee is premised on the adoptee's difference from the immigrant. Thus, the adoptee is confronted with a fundamental dilemma of subjectivity. Adoptive status is understood as cancelling the adoptee's immigrant identity, but as Nordin's statement above suggests, her skin color and physiognomy identify her as "like any other African" in Sweden, an identification she cannot escape. ${ }^{56}$ This identification, and the impossibility of overcoming it, I suggest, is what makes it possible to imagine such a thing as the helsvensk-the "completely Swedish"-which materializes in the presence of "an incorporated but excluded other in 'the Kingdom of Sweden."'57

Hanna Wallensteen, who was adopted from the Hailie Selassie orphanage in Addis Ababa in the early 1970s, explores the uncomfortable relationship of the adoptee to the immigrant in Sweden in her monologue, Veta Sin Plats (Know Your Place). ${ }^{58}$ As Lotta, an eighteen-year-old "of African ancestry" who speaks "unaccented Swedish" and has been jailed for assaulting a black child on a bus in Stockholm, Wallensteen has performed her monologue throughout Sweden to critical acclaim. Speaking from her jail cell, Lotta states that she has no idea why she was arrested. Comparing herself to Swedish immigrants, Lotta notes that immigrants

don't understand that you have to adapt. You can't bring along all of Turkey when you wander into Sweden and just assume you'll be served with a golden spoon. You actually have to make a little effort yourself, too. Now, this might sound as though I am throwing around shit in a stone house, but I came to this country first! You may think this sounds cruel, but that's the way it islife is cruel. And I know that one doesn't say "throwing shit in a stone house." It is "throwing stones in a glass house," and I know that because my parents taught me to speak perfect Swedish. So I don't speak with a Hottentotish accent ["Därför bryter inte jag på

55. Id. at 7 .

56. YNGVESSON, supra note 27, at 141 .

57. See id. at 141-43 for an expanded discussion of this issue. For an argument that the juridico-political order is animated by an exteriority that gives it meaning, see AGAMBEN, supra note 1 , at 18.

58. Hanna Wallensteen, Veta Sin Plats [KNow Your Place] (2000). 
hottentotska"]. That is why I blend in, in this society. That is why I never need to use my fists to make myself understood.

Actually, I'm a good example for people who are just arriving in Sweden. I have lived here since I was nine months old, so I know how one should behave in a civilized country. I don't wipe myself with my hands, and I don't eat with my fingers. But think if I had remained down there? Then I would have had cow shit in my hair, and breasts hanging down to my toes..$^{59}$

The ironic tone that dominates this piece illuminates the paradox of value that adoptees represent in Sweden. The dividing line between immigrant and adoptee is an ambiguous one, marked by the placement of adoptees in elite families, their access to educational resources, jobs, and other advantages that are not available to ordinary immigrants, and especially by the fact that they act and speak perfect Swedish while other immigrants typically do not. At the same time, as most adoptees repeatedly point out, they look like immigrants and are typically mistaken for them. As Lotta suggests, it is the "life script" of the adoptee to embody a paradox in which the "Hottentot" is chosen, longed for, and despised. ${ }^{60}$ This theme is echoed in discussions by adopted adults of their parents' interest in cultural artifacts from the countries where they were born. At a gathering of the Association of Adopted Ethiopians and Eritreans (AEF) in Stockholm a few years ago, a number of those present spoke of their discomfort when parents hung "Ethiopian culture" on the walls of their home, a move that was experienced as a kind of objectification of the essence that brought them to Sweden, the peculiar quality which made them outsiders, like immigrants, in their adoptive nation. ${ }^{61}$

To be adopted in these accounts is to have a kind of body within the body of the adoptee and an international body within the body of the nation, a life script that is determined by the acts of solidarity of wellmeaning parents or well-meaning nations who "saw all the abandoned children on TV in underdeveloped countries" and chose to adopt in addition to, or instead of, giving birth to "their own" children citizens. ${ }^{62}$ Paradoxically, this life script is both "inside" the adoptee (the nation), as

59. Id. at 2 .

60. Id. at 3 .

61. Statements made during the course of the author's fieldwork at a meeting of the Association of Adopted Ethiopians and Eritreans (AEF) in Stockholm in 2000.

62. WALLENSTEEN, supra note 58 , at 3. 
the immaterial thing that defines who the adoptee "is"; but it is also "outside," producing both the adoptee's own experience of "Aha!" when looking in the mirror and the curiosity of well-meaning strangers, who cannot identify her origins and assume she will go "back" to where she "really" belongs. This "immaterial corporality of the "body within the body" 63 does not simply end "at the skin" 64 but materializes around the adopted person as she takes her place in the world, connecting her to and dividing her from others, extending her essence into the spaces that surround her.

An example of this materialization of the non-Nordic body within the body of the Kingdom of Sweden is suggested by the following interview conducted by Anna von Melen, who was adopted from South Korea, with another Swedish adoptee from that country:

I believe that it is definitely easier to be adopted from South Korea than from Ethiopia, for example. A Korean appearance is not connected with refugees. If one sees an Iranian, one thinks immediately "refugee." Everyone who sees me understands that I am adopted, or a voluntary immigrant who works and does her part. That can feel really nice, because otherwise one is standing in a sense outside. I feel uncomfortable in the proximity of immigrants, which I think is because they in some sense unsettle the picture I have formed of myself as Swedish. They remind me that $I$, too, am a kind of immigrant, even though I feel that I am not, because I don't want to see things that way (emphasis added). 65

Here, the presence of the adopted body in the Kingdom of Sweden creates a "zone of indistinction" 66 between what is inside and what is outside, suggesting the ways that the as if belongings of adoption constitute the adoptee, like the refugee, as a kind of "limit figure of life, a threshold in which life is both inside and outside the juridical order,"67 in this way calling into question the foundational terms of national and familial belonging. ${ }^{6}$

63. Slavoj ŽižeK, THe Sublime OBJeCT OF IDEOLOGY 18 (1989).

64. ELSPETH PROBYN, OUTSIDE BELONGINGS 6 (1996).

65. VON MELEN, supra note 50 , at 63.

66. AGAMBEN, supra note 1 , at 25.

67. Id. at 27.

68. See id. at 134 . 


\section{CONCLUSION: CULTURE IN THE SPACE OF No CULTURE}

On her first return visit to Ethiopia in 1997, when she was in her late twenties, Sara Nordin experienced what she described as "a kind of panic attack. I had come to Sweden and then returned to Ethiopia, and perhaps I wouldn't come home [to Sweden] again. I thought, 'One can't make these trips several times. Maybe I will die here."'69 In a parallel experience, Kanthi Grunewald, who was adopted from an orphanage in India when she was four years old and returned with her mother for a visit when she was ten years old, observed to her mother after seeing the children in the orphanage: "Imagine if I had been left there and you had adopted another child and you had come back with her and looked at me?"70 Similarly, Maria Brunn, who returned when she was eleven years old with her mother to visit the Delhi orphanage where she had spent the first ten months of her life, exclaimed to her mother when she first entered the orphanage and saw a chart with statistics on the wall listing how many babies in the orphanage had died and how many had been adopted: "[ $[\mathrm{t}]$ hat would be me if you hadn't come for me, I would be dead, I would be in that column if you hadn't come."71 Maria's and Kanthi's capacity to situate themselves simultaneously inside and outside the orphanage, like Sara Nordin's sense that if she returned to Ethiopia she "wouldn't come home [to Sweden] again"72 are suggestive of the complex workings of an adoption law that purports to establish a clean break between an adoptive child and its preadoptive history, in order to transform one child-the orphanage child, the child who was left behind and might have been dead, might have been me-into the Swedish child-Sara, Hanna, Maria, or Anna.

The clean-break policy is a legal reproductive technology that acts to "free" a child who is understood to be encumbered by properties that constitute it as belonging to particular persons or a particular place, and whose identity is understood to flow from these properties. The child's freedom is made manifest in a declaration of legal orphan status that qualifies the child as available for adoption-that is, to paraphrase Marilyn Strathern's words, as "an anonymously-produced object [that] becomes part of a store on which others draw." 73 The clean break, by mandating the social death of the child that existed prior to the adoption, produces a generalized child who can be classified in terms of

69. YNGVESSON, supra note 27 , at 144 .

70. Id. at 112 .

71. Id. at 113 .

72. Interview with Sara Nordin, in Stockholm, Swed. (Aug. 25, 2002).

73. Marilyn Strathern, Partners and Consumers: Making Relations Visible, in THE LOGIC OF THE GIFT: TOWARD AN ETHIC OF GENEROSITY 292, 302 (Alan D. Schrift ed., 1997). 
such characteristics as age, health status, gender, physiognomy, and national origin, and made available for exchange in an international market in children.

Astrid Trotzig, who was born in South Korea in 1970 and adopted by Swedish parents as an infant, alludes to the generalized child produced for adoption in a passage from her memoir, Blood is Thicker than Water. ${ }^{74}$ Commenting on the emptiness of the phrases in the social study that accompanied her to Sweden:

She looks cute and lovely with oval face, black hair which is rather fewer [sic], black eyes, thin eyebrown [sic], sharp nose and lovely mouth. ... She is a little cute girl who can be grown healthy a proper environment is to be provided [sic]. She can be beloved by anyone. ${ }^{75}$

Trotzig describes her background and history as "a nothing [that] no Social Study can make . . . into a something. The information presented there disappears in a large question mark."76

I suggest that it is in the potential space created by the sentimentalized child-and in silences created by what is not said about the conditions leading to child abandonment-that sending nations infuse their concept of an adoptable child as a "national resource" with specific kinds of value, and receiving nations inscribe their bodies with specific forms of gendered and racialized desire, producing the libidinal economy that underpins the circulation of children in transnational adoption. In this sense, adoption works simultaneously to fragment and to hold together a particular social field, whether familial or national. Adoptive identities always point to what they are not-not immigrants, not Swedes, not "real" children, not "natural" parents or natural families-and in this sense constitute a "nodal point,' a kind of knot of meanings." 77 This knot of meanings, as Žižek argues, "unifies a given field, constitutes its identity: it is, so to speak, the word to which 'things' themselves refer to recognize themselves in their unity."78 But adoptive identities also fragment, in the confusion and ambiguity they produce as performances that are almost, but not quite, "Swedish." The myth of the natural (completely) Swedish identity-the helsvensk-takes shape in this ambiguous space where its difference from the cultural identity of

74. Astrid Trotzig, Blod Är TJOCKare ÄN VATTEn [BlOOd is Thicker Than Water] (1996).

75. Id. at 10-11.

76. Id. at 27 .

77. ŽIžEK, supra note 63 , at 95.

78. Id. at 95-96. 
the adoptee-her black eyes and hair, her exotic appearance, her belonging to "a mighty fine [Ethiopian] culture"79-is "very difficult, sometimes almost impossible to grasp for many." 80 Together, the entanglement of the adoptive with the Swedish suggest how essential adoptive identities are to the "natural" and the "native" that materialize around them, calling them "back" to an ephemeral ground of belonging that is always just out of reach.

79. WALLENSTEEN, supra note 58 , at 3.

80. YNGVESSON, supra note 27 , at 124 . 
